\title{
Exploration on Evolutional Process of Management Accounting from the Perspective of Value Chain Development
}

\author{
Nan Nan \\ Xijing University, Xi'an Shaanxi, 710123, China
}

Keywords: Development perspective of value chain, Management accounting, Evolutional process.

\begin{abstract}
This paper organizes the development and change of the significance of enterprise value chain from the perspective of value chain development, explores the horizontal and longitudinal development process of value chain and then extends to the analysis on social value chain. It combines the evolutional process of enterprise management accounting and the development of value chain and finds out that management accounting should experience the development of activity cost management accounting, strategic management accounting and environmental management accounting process so as to achieve synchronous development with the industrial chain of green supply and ecological park.
\end{abstract}

\section{Introduction}

The development of management accounting in China should meet national conditions. Therefore, the development of management accounting has Chinese characteristics. In the process of analyzing management accounting theory, scholars attached excessive importance to macroscopic classification and analysis and lacked the research on microscopic details. With the presentation of Porter' s value chain, scholars have gradually realized the importance of exploring the development of management accounting from microscopic perspective and applied value chain to the research on management accounting so as to explore the evolutional process of management accounting.

\section{Analysis on problems faced by management accounting and its development demand}

\section{Problems faced by management accounting.}

The broad environment of rapid development of science and technology makes enterprise management more and more advanced. With the development and wide application of computer integrated manufacturing system, high-tech equipment technologies have gradually replaced artificial production of enterprises. Such production mode reduces costs of labor. However, manufacturing costs do not reduce; instead, they constantly increase. In this situation, the method of cost statistics using standard and variable costs as the basis of calculation in accounting management faces many problems.

1) Cost information of value activities cannot be reflected in traditional management accounting

Cost accounting plays a core role in traditional management accounting. Cost accounting analysis can effectively reflect financial information of enterprise accounting and provide basis for decision-making of enterprise leadership. In such accounting activities, cost accounting is conducted based on different classification. In traditional cost accounting mode, the output of products of a category, hours of work spent and quantity of laborers constitute fixed costs of such products. Meanwhile, these factors have positive correlation with fixed costs of products. The occurrence of such phenomenon is irrational, which easily causes the problem of cross-subsidization and wrong cost information of enterprise management and development decision-making. Therefore, enterprise cost accounting should be based on value activities. According to the analysis on Porter' $s$ value chain theory, enterprise value creation is formed by a series of value-added activities. These activities are different, but connect with each other. Cost accounting based on value chain can allow enterprises to divide value-added work and non value-added work effectively, eliminate non value-added work, 
effectively reduce their operating costs and make enterprise decision-making more scientific and reasonable ${ }^{[1]}$.

2) Traditional management accounting information has little effect on enterprise decision-making

Cost information provided by management accounting for enterprises can provide certain decision-making support for enterprises. Enterprise cost accounting includes costs of purchasing, production and sales links of enterprises, which cannot be reflected effectively before material procurement and after-sales link of products. Faced with the competitive market environment and the demand of economic development of globalization and informatization, enterprises should pay attention to cost control in purchasing, production and sales links and meanwhile put a lot of energy in design, research and development stages and develop and innovate products constantly so as to adapt to the changing market demand. Meanwhile, value analysis and environmental cost analysis of consumers play a more and more important role in enterprise development. Enterprise leadership must consider these contents when analyzing enterprise development decision-making so as to guarantee the scientificalness and effectiveness of enterprise strategic decision. However, traditional management accounting does not attach importance to such factors.

3) Traditional management accounting does not have long-term vision.

Traditional management accounting mainly studies internal information of enterprises. That is to say, its research is mainly limited to enterprise production process and its research object is only limited to products successfully researched and developed by enterprises. Therefore, management accounting is generally based on internal environment and existing products of enterprises but neglects the influence of external resource environment in the process of cost control and decision-making analysis. Therefore, it easily causes serious waste of social resources and disordered social competition order. Meanwhile, the failure to attach importance to enterprises in the upstream and downstream of industrial chain and consumer interests will make enterprises unable to obtain good and sustainable competitive advantages through value chain.

\section{Demand of management accounting development of modern enterprises.}

According to the analysis above, traditional management accounting is faced with many problems in enterprise development process. Therefore, under the background of new period, enterprises should further improve management accounting based on value chain, enterprise environment and strategic management so as to achieve better development.

1) Improvement of management accounting should combine value chain theory

Problems of traditional management accounting come from the failure to provide cost information of value activities accurately and effectively to a great extent. The development of management accounting is limited by this. Through the combination with value chain theory, it can effectively recognize value activities of enterprises so as to reflect cost information effectively and eliminate disadvantages of cost accounting in traditional management accounting. Value chain theory mainly aims at managing the operation process formed by product value better. The operation process includes basic operation and auxiliary operation activities of enterprises. Management contents include value-added operation, non value-added operation and the elimination of non value-added operation in the process of value formation. The management over such contents can make up for the deficiency of traditional cost management ${ }^{[2]}$.Meanwhile, the analysis on value chain should not only pay attention to internal activities of enterprises, but also pay attention to external competitive activities of enterprises and expand the visual angle of competitive advantages of enterprises.

2)Management accounting should provide decision-making information from strategic perspective

Management accounting work should provide specific information for personnel in the specific management field so as to provide reliable basis for enterprise decision. Therefore, management accounting should not only consider tactical features of decisions, but also consider the scientificalness of decision-making from strategic perspective in the process of decision-making. The provision of decision-making information and decision-making in traditional management accounting are based on internal environment of enterprises. The mode of relevant guidance over 
business activities of enterprises in tactical directions through the analysis on internal production activities of enterprises easily causes the phenomenon of wrong decision. Under the market background of new period, facing the fierce competition in the market and the diversification of development, enterprises must stand on a strategic height, use internal activities of enterprises as the basis and meanwhile pay attention to relevant information and direction of competitors during decision-making so as to make enterprise decisions more scientifically, prospectively and strategically and promote better development of enterprises.

3) The development of management accounting should consider environmental factors.

The rapid development of market economy promotes the process of economic globalization. During economic development, problems in energy and environment incurred by it become prominent gradually. Enterprises in such social environment cannot avoid their negative influence. Therefore, enterprise development must consider environmental factors. Therefore, the development and application of a series of green energy management accounting concepts and methods such as social responsibility accounting and carbon accounting have emerged, which provide effective basis for enterprise environmental management. Management accounting undertakes the task of providing decision-making information for enterprises. Therefore, it must pay attention to environmental information at all times and strictly control environmental costs of production. Therefore, the development of management accounting must be based on environmental factors. In terms of enterprise management, the starting point of its development is no longer economic benefit. Meanwhile, it is also required to consider environmental benefit and value increment in ecological protection.

\section{Evolutional process of management accounting from the perspective of value chain development}

\section{Analysis on value chain tool.}

Value chain concept was first put forward by American managerialist Michael Porter. After value chain concept was put forward, it won wide attention of enterprises immediately and became the most advanced management idea. It has promoted the development of management and produced great positive influence on the development of management accounting. Porter defined value chain as the completion of a series of activities in enterprises, including the input of raw materials and terminal use of consumers in his famous work Competitive Advantages. The proposal and application of value chain have attracted a lot of scholars for detailed analysis on it. Through the decomposition of value chain activities, enterprises can identify advantages and disadvantages of enterprise activities effectively and then take corresponding measures positively to control production costs. From this perspective, enterprises should center on internal value chain in study, pay attention to the whole process of production and obtain more competitive advantages through the control over internal production costs.

\section{Analysis on internal value chain of enterprises.}

The analysis on internal value chain of enterprises mainly involves in-depth research on internal value activities of enterprises. Value activities from the perspective of value chain include purchasing, production and sales links of enterprises. Through the analysis on internal value chain, enterprises can recognize the most basic and important value chain in enterprises and conduct more detailed analysis on the value chain. According to the degree of role in value promotion, operation activities of enterprises can be classified into value-added work and non value-added work activities. Meanwhile, value-added work activities can be classified into direct and auxiliary value-added work activities. To improve internal activity value of enterprises, enterprises should pay attention to improve the efficiency of direct value-added work activities. For auxiliary value-added work activities, enterprises should control the supply of its resources. For non value-added work activities, enterprises should control its occurrence rate as much as possible when unable to transform them into value-added work activities. The analysis on internal value chain is an important method for enterprises to obtain low-cost competitive advantages. It is thus clear that the analysis on internal value chain plays an irreplaceable role in enterprises. 


\section{Combine activity cost method and internal value chain of enterprises.}

Enterprise cost analysis based on activity cost method should start from the interior of enterprises and reduce enterprise costs through the control over each link in enterprise production. Internal value chain should be based on internal work activities of enterprises so as to analyze factors that might cause the increment of enterprise value. Their combination can make enterprise management accounting achieve high-efficiency development and make activity cost management accounting obtain diversified development connotations. First, activity cost management accounting can use internal value chain of enterprises as the premise of analysis. The thought of activity cost and value chain have the same effect. Both of them conduct analysis work based on internal basic work of enterprises so as to seek for work links reducing costs and make enterprises obtain low-cost competitive advantages. The application of activity cost method is an extension of value chain development ${ }^{[3]}$.Second, the combination of activity cost method and internal value chain can make traditional cost analysis of enterprises pay more attention to the analysis on internal activities and allow enterprises to obtain more important information source. Finally, activity cost management accounting can realize constant optimization and improvement based on internal value chain of enterprises and improve resource allocation rate of enterprises.

\section{Result of evolution and future development trend of management accounting from the perspective of value chain development}

\section{Result of evolution of management accounting from the perspective of value chain development.}

Connotations of enterprise value chain gradually transit to horizontal and longitudinal value chain analysis from internal value chain analysis and finally extend to the analysis on social value chain and then achieve further enrichment and improvement. On the one hand, value chain analysis gradually tends to be improved and lays a foundation for enterprise development and expansion. Its analysis process transforms into external environment from internal environment and then transits to social effect. This reflects the change of operating decision concept of enterprises. Meanwhile, the development of value chain and that of enterprise management accounting supplement each other. Their crossing development makes the development process of value chain clearer and makes its connotations realize diversified development. The development of value chain promotes the course of internationalization of management accounting in China and gradually adapts to market environment. In the development of value chain, activity cost management accounting is based on activity cost method and highlights the value of combination of activity cost method and internal value chain.

Development trend of evolution of management accounting from the perspective of value chain development.

\section{1) Competition of green supply chain}

The proposal of low-carbon economy, green enterprises and sustainable development makes value chain management of enterprises gradually transform into supply chain management. Therefore, traditional enterprise competition gradually transforms into supply chain competition. It can also be understood that future market competition will mainly involve green supply chain. The scope of enterprise cost management gradually changes into product life cycle from the perspective of environmental management from the perspective of producers. Therefore, cost control through the analysis from the perspective of green supply chain is more scientific than value chain analysis.

2) Combination of eco-industrial park management and value chain management

The analysis on evolutional process of management accounting above is conducted from the perspective of enterprises. However, to realize low-carbon economic management and sustainable development of enterprises, it is also necessary to conduct analysis and expansion from the perspective of industrial park so as to form the management mode with the combination of eco-industrial park and value chain. 


\section{Conclusion}

In conclusion, the integration of environmental management concept into enterprise management accounting can effectively make up for deficiencies of traditional management accounting. Connotations of environmental management accounting can achieve diversified development through the expansion of new perspective in combination with new method. The combination and development of environmental management accounting and green supply chain and eco-industrial park is still an arduous task. Further efforts of relevant personnel and institutions are required.

\section{References}

[1] Wang Man, Wang Jingqi. Study on Management Accounting Decision-making Method Based on Value Chain, Study on Financial Issues, 2012(9):18-24.

[2] Liu Da, Zhou Hang. Conjunction of Systematic Thought of Circular Economic Value Chain and Management Accounting Method, Economic Survey, 2012(1):77-81.

[3] Li Mingbin. Study on Management Accounting Decision-making Method Based on Value Chain, China Business and Trade, 2013(25):106-107. 